\title{
ReLAInEP
}

\section{A CRIAÇÃO DO CONHECIMENTO EM PAUTAS JORNALÍSTICAS DE UMA EMISSORA DE TV: O ESTUDO DE CASO DE UM TELEJORNAL DIÁRIO}

\author{
Aline Bohacuk Pavaneli ${ }^{1}$ \\ Anderson Luís Fröhlich ${ }^{2}$ \\ Helena de Fátima Nunes Silva ${ }^{3}$
}

\begin{abstract}
RESUMO: Este estudo busca identificar os elementos do processo de criação do conhecimento e avaliar as condições do ambiente de trabalho para a criação de pautas jornalísticas em um telejornal diário de uma emissora de televisão da Região Sul do Brasil. A revisão teórica contempla o processo de criação do conhecimento japonês, descrito por Nonaka e Takeuchi (1997), que leva em consideração o conhecimento tácito e o conhecimento explícito dos indivíduos da organização, passando pelos conceitos de jornalismo, telejornalismo e pauta. Trata-se de uma pesquisa de caráter descritivo e qualitativo, se encaixando na categoria estudo de caso. Para a coleta de dados foram realizadas duas entrevistas e a observação das etapas de produção da pauta a partir de um protocolo. Os resultados demonstraram que a construção da pauta do telejornal possui 34 etapas envolvendo toda a equipe. Pela natureza dinâmica do telejornalismo, as cinco condições capacitadoras para a criação do conhecimento estão presentes em grande parte das etapas da criação do conhecimento na pauta.
\end{abstract}

Palavras-chave: Criação do conhecimento. Telejornalismo. Gestão do Conhecimento. Pauta.

ABSTRACT: This research try to identify the elements from the knowledge creation process and analyze the correct condition on the work environment where the journalistic scripts are created in a daily television news in a television company in the South of Brazil. The theory is based on the Japanese knowledge creation process writen from Nonaka and Takeuchi (1997), where take the tacit knowledge and the explicit knowledge from the individuals in the enterprise, passing through journalistic concepts, TV journalism and script. This is a descriptive and qualitative research that fits as a case of study. The procedure to get the data to this research was the personal interview and the observation of the stages of the production of the scripts from the observational protocol. The results showed 34 steps to make the script that involved all team. From the dynamic nature of TV journalism, the five capable conditions

\footnotetext{
${ }^{1}$ Universidade Federal do Paraná - UFPR. alinepavanelli@ gmail.com

${ }^{2}$ Universidade Federal do Paraná - UFPR.

${ }^{3}$ Universidade Federal do Paraná - UFPR. helenanunes@ufpr.br
} ReLAInEP - Revista Latino-America de Inovação e Engenharia de Produção, Curitiba, PR, Brasil, v. 3, n. 4, p. 75-95, 2015. 


\section{ReLAInEP}

for knowledge creation are present on the most steps of the creation of knowledge for the script.

Keywords: Knowledge creation. TV news. Knowledge Management. Script.

RESUMEN: Este estudio busca identificar los elementos del proceso de creación de conocimiento y evaluación de las condiciones del entorno laboral para la creación de pautas periodísticas en un programa diario de noticias de un canal de televisión en el sur de Brasil. La revisión de la literatura cubre el proceso de creación del conocimiento japonés, descrito por Nonaka y Takeuchi (1997), que toma en cuenta el conocimiento tácito y explícito de las personas de la organización, a través de los conceptos de periodismo, el periodismo de televisión y orden del día. Se trata de un estudio descriptivo y cualitativo, encajando el estudio categoría del caso. Para la recolección de datos se realizaron dos entrevistas y observación de las fases de la producción de la pauta. Los resultados mostraron que la construcción de la pauta del telediario tiene 34 pasos que involucran a todo el equipo. Por naturaleza dinámica de las noticias de televisión, las cinco condiciones propicias para la creación de conocimiento están presentes en la mayoría de las etapas de la creación de conocimiento en la pauta.

PALABRAS ClAVE: Creación de Conocimiento. Periodismo televisivo. Gestión del Conocimiento. Pauta.

\section{INTRODUÇÃO}

Capturar dados, processá-los e transformá-los em informação nunca foi tão fácil. A capacidade de coleta de dados por meio de novas tecnologias tem um alcance cada dia maior. Um exemplo é o advento dos telefones inteligentes (smartphones), que permitem a criação, captura e compartilhamento de informações em qualquer lugar do mundo.

Tão importante quanto à transmissão dessas informações e o seu armazenamento, é saber como essas informações podem ser usadas e transformadas em conhecimento indispensável para a tomada de decisão das organizações. Nesse contexto, a Gestão do Conhecimento se apresenta como alternativa de ordenação ao caos de dados coletados, transformando-os em informação útil, com objetivo final de gerar a inovação organizacional.

Nas organizações não é diferente. A coleta de dados e a criação do conhecimento de uma organização vai além da elaboração de manuais e mapeamento de processos desenvolvidos, ou seja, o processamento de informações para alcançar seus objetivos. Mas está diretamente ligado ao conhecimento tácito dos indivíduos, que é pessoal e difícil de organizar (NONAKA; TAKEUCHI, 1997).

ReLAInEP - Revista Latino-America de Inovação e Engenharia de Produção, Curitiba, PR, Brasil, v. 3, n. 4, p. 75-95, 2015. 


\section{ReLAInEP}

As empresas jornalísticas, que têm como objetivo produzir conteúdo e divulgar informações sobre os acontecimentos de interesse público passam diariamente pelo processo de criação do conhecimento, a partir do momento em que definem suas pautas, produzem o conteúdo jornalístico e divulgam as notícias.

O estudo será baseado na Teoria da Criação do Conhecimento Organizacional de Nonaka e Takeuchi que afirmam que o conhecimento de uma organização vai além do explícito, aquele que é formalizado e sistematizado, mas que passa pelo conhecimento tácito de cada indivíduo que faz parte da organização e colabora para a criação de um novo conhecimento. Como o conhecimento tácito tem natureza subjetiva, precisa ser compartilhado de uma forma que qualquer pessoa possa entender. Segundo Nonaka e Takeuchi '"é exatamente durante o tempo em que essa conversão ocorre - de tácito em explícito e (...) novamente em tácito - que o conhecimento organizacional é criado". $(1997$, p. 8)

O objetivo deste estudo é identificar os elementos do processo de criação do conhecimento e avaliar as condições do ambiente de trabalho para a criação de conhecimento nas pautas jornalísticas de um telejornal de uma das maiores emissoras de televisão da Região Sul do Brasil.

\section{REFERENCIAL TEÓRICO}

A Gestão do Conhecimento enquanto disciplina independente, visto que ambos conceitos aparecem separadamente em várias outras áreas, surge a partir da década de 80 (COSTA, KRUCKEN, ABREU, 2000, p. 31). O termo foi cunhado inicialmente para “... descrever a criação e o uso de repositórios eletrônicos de dados e informações com uma estrutura orientada para o conhecimento. (ibid, p. 31). Uma coisa é certa, a era da informação chegou e ninguém duvida disso. Inicialmente foram depositadas todas as esperanças para a exploração do potencial da era da informação nos sistemas informatizados. Não obstante, segundo McGee e Prusak (1994, p. 6):

O contraste entre os investimentos maciços em tecnologia da informação, seu evidente potencial transformador, e os lucros auferidos contribuíram para uma percepção crescente entre as organizações de que é preciso reexaminar muitos de seus pressupostos fundamentais quanto à estruturação e uso da informação e da sua tecnologia. ... É triste precisar dizer isto, mas a verdade é que muito pouco desse sonho se realizou.

ReLAInEP - Revista Latino-America de Inovação e Engenharia de Produção, Curitiba, PR, Brasil, v. 3, n. 4, p. 75-95, 2015. 


\section{ReLAInEP}

Demorou, mas a consciência coletiva de empresários e pesquisadores concluiu que somente organizar e armazenar as informações não garante o correto uso da mesma e muito menos geram vantagem competitiva.

Porém, a dificuldade de definição e delimitação conceitual faz com que seu amadurecimento enquanto disciplina seja gradativo. Para Alvarenga Neto (2008, p. 2) a Gestão do Conhecimento é um fenômeno multifacetado e complexo, polêmico e controverso. Segundo Rowley (1999; apud COSTA, KRUCKEN, ABREU, 2000, p. 32) a Gestão do Conhecimento está diretamente vinculada ao amadurecimento das próprias organizações e sua crescente consciência da importância da geração constante de conhecimento o que torna a conceituação dessa disciplina uma tarefa difícil. Alvarenga Neto (2008, p. 3) concluiu em sua pesquisa que “... as organizações que afirmavam ter programas de gestão do conhecimento praticavam, na verdade, a gestão estratégica da informação ...” Entrementes, algumas asseverações para sua conceituação são sugeridas como segue.

Para Broadbent (apud LOUGHRIDGE,1999; COSTA, KRUCKEN, ABREU, 2000, p. 33), trata-se da aquisição, criação, armazenagem, aplicação e reutilização do conhecimento. Malhotra (1998, apud COSTA, KRUCKEN, ABREU, 2000, p. 32) define gestão do conhecimento como “ ... fator crítico para a adaptação, sobrevivência e competência das organizações frente a mudanças ambientais...” e que isso engloba “... processos organizacionais procurando combinar sinergisticamente a capacidade de processamento de dados e informações das tecnologias de informação, e a capacidade criativa e inovativa dos seres humanos.” Já para Miskie (1997, apud COSTA, KRUCKEN, ABREU, 2000, p. 32), é na soma dos conhecimentos dos indivíduos, suas habilidades pessoais, e o conhecimento explicitado a partir daí que acontece a geração do conhecimento. Ele sugere que de forma intencionalmente estratégica a gestão do conhecimento deveria ser promovida como uma cultura, integrando ciência e arte, de modo a promover um incremento na capacidade de ação de um indivíduo e, consequentemente, na organização.

Von Krogh; Ichijo; Nonaka (2001, p.15) definem o conhecimento como uma "crença verdade e justificada". No entendimento dos autores são “... as pessoas quem justificam a veracidade de suas crenças com base em observações do mundo; " e que essas observações

ReLAInEP - Revista Latino-America de Inovação e Engenharia de Produção, Curitiba, PR, Brasil, v. 3, n. 4, p. 75-95, 2015. 


\section{ReLAInEP}

são de caráter pessoal, sendo dependentes da experiência pessoal e da sensibilidade do indivíduo.

Já para Nonaka; Takeuchi (1997) a tarefa da gestão do conhecimento é proporcionar um ambiente propício ( $b a$ ) para o surgimento desse conhecimento. E esta deve estar impregnada na cultura da empresa e precisa ser promovido e apoiado pela alta direção. Gestão do Conhecimento, então, deixa de ser um departamento ou uma cadeia e passa a ser uma força motriz transformadora onde informações e conhecimento vem a tornar-se um constante reinventar-se em prol dos objetivos da organização.

\subsection{A criação do conhecimento}

A principal diferença entre os conceitos ocidentais da criação do conhecimento para o modelo japonês está justamente na definição de conhecimento tácito e conhecimento explícito. Cabe destacar que muito embora diversos autores (Kogut e Zander (1992), Bierly e Chakrabarti (1996), Spender e Grant (1996), Leonard e Sensiper (1998), Bontis (1999), Zack (1999), Nonaka, Toyama e Konno (2000), Krogh, Ichijo e Nonaka (2001) entre outros) tenham trabalhado a temática conhecimento, seja do ponto de vista da geração, da gestão ou da estratégia, o processo de criação de conhecimento tem Nonaka e Takeuchi como autores seminais e de maior expressão no assunto. Desta forma, foram adotados como direcionadores do estudo.

Conforme Leonardi e Bastos (2014) este tema passou a ser estudado também nas relações entre empresas, tal como a preocupação em Llerena e Ozman (2013) que abordam o efeito da irreversibilidade na escolha de parcerias colaborativas inter-empresariais e também tem sido discutido em outras áreas, como destacado em Liu e Ma (2013), onde exploram o estado das atividades de criação de conhecimento em escalas espaciais e temporais de biocientistas.

\subsubsection{A criação do conhecimento}

A criação de conhecimento é profundamente interativa, tanto as pessoas como o ambiente são afetados por ações individuais. O conhecimento é inseparável dos processos temporais de criação, interação e interpretação tanto como o contexto ou espaço de criação (HAUTALA; JAUHIAINEN, 2014).

ReLAInEP - Revista Latino-America de Inovação e Engenharia de Produção, Curitiba, PR, Brasil, v. 3, n. 4, p. 75-95, 2015. 


\section{ReLAInEP}

Nonaka e Takeuchi (1997) identificaram três características que estão presentes no processo de transformação do conhecimento tácito em explícito: a metáfora e analogia, que ajudam a transmitir uma informação difícil de ser explicada por meio do sentido figurado; o compartilhamento do conhecimento pessoal, que precisa ser transmitido para os outros de alguma forma para que a ideia possa ser desenvolvida pelo grupo e a ambiguidade e a redundância, sendo que a primeira contribui para dar uma direção e pode permitir a criação do conhecimento a partir do caos e a segunda porque facilita o entendimento daquilo que um indivíduo está tentando compartilhar.

\subsubsection{A conversão do conhecimento}

Há quatro modos de conversão do conhecimento: socialização, externalização, combinação, internalização (NONAKA; TAKEUCHI, 1997).

A socialização é a transformação do conhecimento tácito em conhecimento tácito e pode ser identificado como o compartilhamento de experiências por um indivíduo. A socialização gera o conhecimento compartilhado.

A externalização é a transformação do conhecimento tácito em conhecimento explícito e se dá quando alguém tenta explicar uma ideia a partir da linguagem falada ou escrita. Como muitas vezes esse é um processo difícil por sua inconsistência, há interação entre os indivíduos. A externalização gera o conhecimento conceitual, uma diretriz para a criação do conhecimento sistêmico.

A combinação é a transformação do conhecimento explícito em conhecimento explícito e acontece quando há combinação de conhecimentos explicitados por meio de documentos, reuniões, uma aula, etc. A combinação cria o conhecimento sistêmico, que é a simulação de criação de um produto.

A internalização é a transformação do conhecimento explícito em conhecimento tácito e ocorre quando há um processo de aprendizado durante a realização de uma tarefa, por exemplo. É necessário que o conhecimento seja documentado para que seja internalizado e então transformado em conhecimento tácito. A internalização gera o conhecimento operacional, as técnicas através das quais um produto será produzido, por exemplo. Por meio da experiência, muitas vezes o conhecimento operacional gera um novo ciclo de criação do conhecimento. Os processos podem ser mais bem entendidos na tabela abaixo:

O processo de conversão do conhecimento

ReLAInEP - Revista Latino-America de Inovação e Engenharia de Produção, Curitiba, PR, Brasil, v. 3, n. 4, p. 75-95, 2015. 


\section{ReLAInEP}

\begin{tabular}{|l|l|l|}
\hline $\begin{array}{l}\text { Modos de conversão do } \\
\text { conhecimento }\end{array}$ & Transformação & $\begin{array}{l}\text { Tipo de } \\
\text { conhecimento }\end{array}$ \\
\hline Socialização & De tácito para tácito & Compartilhado \\
\hline Externalização & De tácito para explícito & Conceitual \\
\hline Combinação & De explícito para explícito & Sistêmico \\
\hline Internalização & De explícito para tácito & Operacional \\
\hline
\end{tabular}

Fonte: Nonaka e Takeuchi, (1997)

De acordo com Nonaka e Takeuchi, todo esse processo gera a espiral de criação do conhecimento: "A criação do conhecimento é um processo em espiral, que começa no nível individual e vai subindo, ampliando comunidades de interação que cruzam fronteiras entre seções, departamentos, divisões e organizações" (1997, pg. 82). A Figura 1 ilustra o processo.

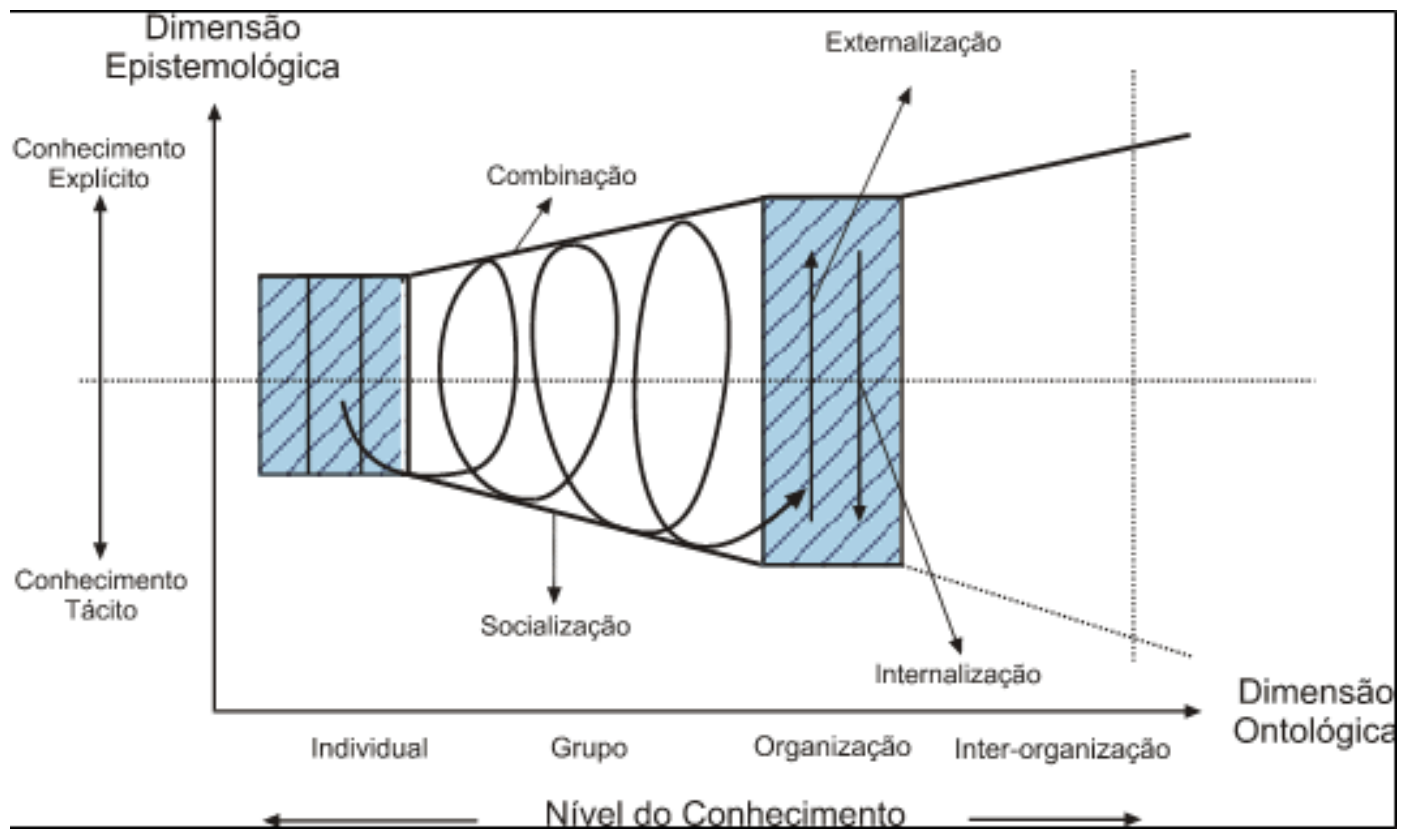

Figura 1: Espiral do conhecimento organizacional

Fonte: Nonaka e Takeuchi, (1997, p. 82)

Um dos principais facilitadores para o trabalho com esse formato do conhecimento são as redes de trabalho que ligam pessoas experientes e preparadas para atuar em grupo, interagindo basicamente por meio de ampla troca de conhecimentos tácitos (SILVA, 2004).

No artigo de Nonaka e Toyama (2005), The Theory of the Knowledge-Creating Firm:

Subjectivity, Objectivity and Synthesis os autores trazem uma caso pontual de uma empresa, onde o conhecimento é criado por meio de interações dinâmicas com o meio

ReLAInEP - Revista Latino-America de Inovação e Engenharia de Produção, Curitiba, PR, Brasil, v. 3, n. 4, p. 75-95, 2015. 


\section{ReLAInEP}

ambiente. O modelo é composto por sete componentes básicos: o processo SECI de diálogos e práticas; a visão de conhecimento e condução de objetivos, o que dá uma direção e energia para o processo SECI; Ba como um lugar existencial para o processo SECI; ativos de conhecimento, que são entradas e saídas do processo SECI; o meio ambiente como um ecossistema de conhecimento e as multicamadas do Ba. Uma vez que o conhecimento é criado por meio de uma interação dinâmica, é necessário que a liderança numa empresa de criação de conhecimento tenha um compromisso ativo de todos os membros da organização, e não apenas de algumas elites. (LEONARDI; BASTOS, 2014)

\subsubsection{Condições capacitadoras para a criação do conhecimento}

A organização precisa oferecer o contexto apropriado para a criação do conhecimento tanto em grupo como individualmente. Nonaka e Takeuchi(2008) listam cinco condições que promovem a espiral do conhecimento:

a) Intenção: Tem como objetivo nortear a produção de conhecimento de uma organização e está diretamente ligada à visão e aos valores da empresa. É a partir desta que se dá o impulsionamento da espiral do conhecimento, mas o conhecimento precisa ser avaliado e julgado a partir da intenção organizacional.

b) Autonomia: os membros de uma organização deveriam poder agir com autonomia e definir suas tarefas sozinhos, em busca dos objetivos finais da organização. Essa autonomia representa, também, uma horizontalidade em relação às funções exercidas, fazendo com que toda a equipe caminhe junto em busca do conhecimento, do início ao fim e não de maneira alternada, dependendo do seu setor de atuação.

c) Flutuação e caos criativo: A flutuação explora a "ambiguidade, a redundância ou o ruído (...) para melhorar seu (...) sistema de conhecimento". (NONAKA e TAKEUCHI, 2008, pg.76). Ela implanta uma decomposição das rotinas da organização e tira os indivíduos da sua zona de conforto, fazendo-os pensar no modo como interagem com o mundo. Já o caos pode surgir durante uma crise ou ser gerado pela gerência a partir de "metas desafiadoras". O "caos criativo" ocorre quando os indivíduos de uma organização estão focados na resolução de um problema. Os dois levam à reflexão sobre o modo de executar tarefas e pensar dos indivíduos que formam a organização e, consequentemente, podem gerar novas ideias.

ReLAInEP - Revista Latino-America de Inovação e Engenharia de Produção, Curitiba, PR, Brasil, v. 3, n. 4, p. 75-95, 2015. 


\section{ReLAInEP}

d) Redundância: facilita a comunicação entre diferentes níveis da organização por meio do compartilhamento de conceitos que ajudam na criação do conhecimento. A informação redundante geralmente é compartilhada durante o processo de criação do conhecimento e está ligada ao conhecimento tácito. "A redundância de informações permite o “aprendizado por intromissão" na esfera de percepção de cada indivíduo" (NONAKA e TAKEUCHI, 2008, pg.78). A redundância também é útil para controlar as ações dos indivíduos e para fazer entender o papel de cada um dentro da empresa. Uma das formas de criar a redundância é a rotatividade de funções, que ajuda a desenvolver habilidades e aumentar fontes de informação. $O$ indivíduo que passa por diferentes funções acumula diferentes tipos de informação que ajudam no processo de criação do conhecimento. Reuniões e encontros fora do horário de trabalho também ajudam a criar a redundância, facilitando a troca de conhecimentos. É importante que as informações criadas sejam armazenadas em local de fácil acesso.

Variedade de requisitos: a organização precisa reagir frente aos desafios como um organismo único, para isso a informação acessível a todos os níveis da organização. A rotatividade de funções e constantes reestruturações também diminuem o tempo e a eficácia da resposta da empresa a algum problema.

\subsubsection{Modelo das cinco fases para a criação do conhecimento}

O exemplo ideal do processo de criação do conhecimento compreende cinco fases, exemplificadas na Figura 2.

ReLAInEP - Revista Latino-America de Inovação e Engenharia de Produção, Curitiba, PR, Brasil, v. 3, n. 4, p. 75-95, 2015. 


\section{ReLAInEP}

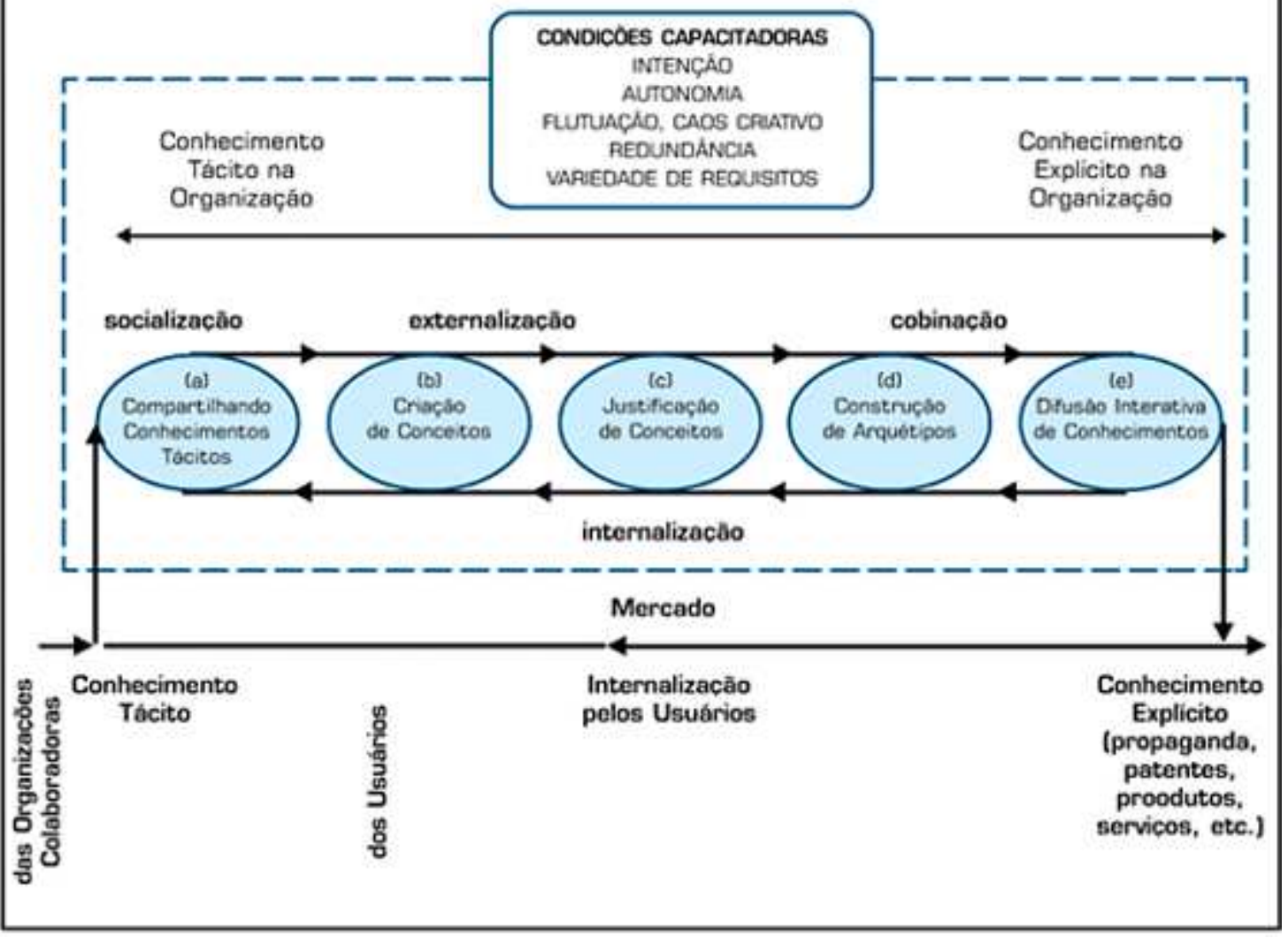

Figura 2 - Modelo de cinco fases do processo de criação do conhecimento organizacional.

Fonte: Nonaka e Takeuchi (1997)

$1^{\text {a }}$ fase - Compartilhamento do conhecimento tácito: Nesta fase os indivíduos formam um grupo para alcançar um objetivo e realizam a interação por meio da exposição do seu conhecimento tácito através do diálogo. Nesta fase identificamos a socialização e as cinco condições capacitadoras para a criação do conhecimento. Com a interação com o ambiente externo há acúmulo de conhecimento tácito e explícito.

$2^{\mathrm{a}}$ fase - Criação de conceitos: com a interação dos conhecimentos dos indivíduos que formam o grupo e por meio da reflexão se chega a um conceito. De acordo com os autores, o processo é facilitado por métodos de raciocício como dedução, indução e abdução. Essa fase equivale à externalização e também depende das cinco condições capacitadoras para a criação do conhecimento.

ReLAInEP - Revista Latino-America de Inovação e Engenharia de Produção, Curitiba, PR, Brasil, v. 3, n. 4, p. 75-95, 2015. 


\section{ReLAInEP}

$3^{\text {a }}$ fase - Justificação de conceitos: após a criação de conceitos é necessário justificá-los. É também uma forma de explicitar tudo o que foi definido pelo grupo e verificar se estão dentro da visão e valores da organização. A redundância e a intenção são as condições capacitadoras para a criação do conhecimento presentes nesta fase, que equivale à internalização.

$4^{\mathrm{a}}$ fase - Construção de um arquétipo: a partir do conceito, cria-se um arquétipo do processo de um novo produto ou serviço. É preciso planejar o protótipo como uma maquete esquematizando tudo o que foi proposto. A fase equivale à combinação e a redundância, a variedade de requisitos e a intenção organizacional facilitam o processo.

$5^{\text {a }}$ fase - Difusão interativa do conhecimento: mostra que o processo de criação do conhecimento organizacional é contínuo. A partir da criação de um protótipo, o compartilhamento entre outros setores pode gerar outras idéias e mudanças no modelo. Todo o processo é cíclico e também pode afetar concorrência, vendedores e clientes da organização, cujos feedbacks podem gerar um novo processo de criação do conhecimento. Nesta fase a autonomia, a flutuação, a intenção e a redundância são facilitadores. (NONAKA; TAKEUCHI, 1997)

\subsection{Jornalismo, telejornalismo e pauta}

O jornalismo é o exercício profissional de coletar, organizar e divulgar informações de interesse público. A atividade pode ser concretizada por vários meios como jornais impressos, rádio, televisão e Internet, entre outros.

Um dos principais diferenciais do jornalismo de televisão é a união entre áudio e imagem. Apesar de não possuir a agilidade do rádio, que pode ser ouvido de qualquer parte e transmitir notícias com mais rapidez, a TV possui a vantagem da imagem aliada ao som, o que facilita a compreensão do público. Para Paternostro (1999, p. 64), “a TV mostra e o telespectador vê: ele se informa, está recebendo a notícia e ampliando seu conhecimento".

As novas tecnologias já permitem que a TV se aproxime da agilidade do rádio com a possibilidade de transmissões ao vivo, no momento em que o fato está ocorrendo. $\mathrm{O}$ alcance da TV é muito grande, "não distingue classe social ou econômica, atinge a todos" (PATERNOSTRO, 1999, p. 64).

O meio tem também o poder de envolver o telespectador nas histórias contadas, por meio da identificação com os jornalistas.

ReLAInEP - Revista Latino-America de Inovação e Engenharia de Produção, Curitiba, PR, Brasil, v. 3, n. 4, p. 75-95, 2015. 


\section{ReLAInEP}

Por sua natureza audiovisual, o telejornal exige uma equipe maior que outros meios. Os jornalistas se dividem em diversas funções como: pauteiro ou produtor, editor, editorchefe, repórter, repórter cinematográfico, chefe de redação, entre outras.

O pauteiro é responsável pela produção da pauta. Ele buscará meios de se informar dos fatos que estão ocorrendo ou que irão acontecer e levantar temas que podem ser transformados em reportagens. A pauta é o produto final do trabalho de um pauteiro e é definida por Paternostro como a "previsão de assunto de interesse jornalístico. É o roteiro dos temas que vão ser cobertos pela reportagem". (1999, p. 147). É a pauta que dará ao repórter as informações básicas sobre a matéria que irá produzir como, horário e local das entrevistas, nomes dos entrevistados e sobre o que cada um vai falar, além de apresentar a proposta da matéria, o que ela pretende mostrar aos telespectadores e por qual enfoque.

\section{METODOLOGIA}

Trata-se de uma pesquisa descritiva, pois busca-se descrever características de uma população ou fenômeno ou estabelecer relações entre variáveis. Em relação aos procedimentos técnicos, a pesquisa é bibliográfica e se enquadra na modalidade estudo de caso. O estudo de caso foi escolhido por permitir o aprofundamento de "um ou poucos objetos, de maneira que permita seu amplo e detalhado conhecimento" (GIL, 2002, p. 54). A modalidade exige a criação de um protocolo para a coleta e análise de dados relacionados à produção de pautas para o telejornal.

Por sua natureza metodológica, a análise dos dados será predominantemente qualitativa, por isso o estabelecimento de um quadro de referência teórico, que ajude a definir a forma de avaliação e a elaboração do relatório final, é imprescindível (GIL, 2002, p. 141).

Em relação aos procedimentos de coleta de dados, primeiro passo foi definir um roteiro para uma entrevista com integrantes da equipe do telejornal. Optou-se por 21 questões preestabelecidas que tinham como objetivo levantar informações para entender todo o processo de trabalho da equipe, do surgimento da ideia de uma pauta até a sua exibição no telejornal.

Foram escolhidos dois integrantes da equipe, que possuem participação direta em toda a cadeira de produção de uma pauta: um dos editores chefes, jornalista responsável pelo telejornal e uma coordenadora de reportagem, jornalista que ajuda na definição das pautas e

ReLAInEP - Revista Latino-America de Inovação e Engenharia de Produção, Curitiba, PR, Brasil, v. 3, n. 4, p. 75-95, 2015. 


\section{ReLAInEP}

na distribuição das matérias entre os repórteres. Os dois foram escolhidos pelo trabalho direto com os produtores do telejornal e pela visão geral que precisam ter de toda a produção de reportagens.

A partir da revisão teórica sobre o processo de criação do conhecimento de Nonaka e Takeuchi, foi elaborado um protocolo de observação com os seguintes itens: etapas de produção da pauta, envolvidos, modos de conversão e condições capacitadoras.

O objetivo do protocolo foi identificar todas as etapas da criação de uma pauta até a exibição da matéria no telejornal.

Com o embasamento teórico, a partir da análise descritiva de todo o processo de produção do telejornal, os autores buscaram identificar os modos de conversão e as condições capacitadoras presentes em cada etapa de produção do telejornal.

\section{RESULTADOS}

A partir das entrevistas foi possível entender o funcionamento de toda a estrutura da empresa voltada para o objeto de estudo.

O telejornal é exibido de segunda a sábado, a partir das 12 horas e seu tempo de duração varia, mas tem uma média de 40 minutos. O telejornal tem o primeiro bloco local com matérias da Capital, Região Metropolitana e Litoral e três blocos estaduais, com matérias produzidas por outras sete emissoras da rede distribuídas pelo Estado.

A equipe é formada por dois editores-chefes, dois apresentadores-editores, um apresentador da previsão do tempo que também é editor, quatro editores e três produtores. Todos os editores e apresentadores trabalham no período da manhã. Um produtor trabalha no período da manhã, auxiliando em apurações de assuntos do dia, de notas de posicionamento e pautando material para o período da tarde ou para a próxima manhã. No período da tarde são dois produtores que pautam as matérias que serão produzidas pelos repórteres na manhã seguinte. São três coordenadores de reportagem - um pela manhã, uma pela tarde e outro tarde/noite - que cuidam das logísticas das equipes que estão na rua e ajudam a definir pautas com produtores e editores-chefes.

Os editores-chefes definem que matérias serão produzidas e a forma de produzi-las (número de entrevistados, o foco, etc.), mas muitas vezes essa discussão passa primeiro pelo coordenador de reportagem, que faz uma avaliação prévia e pode definir sozinho as pautas.

ReLAInEP - Revista Latino-America de Inovação e Engenharia de Produção, Curitiba, PR, Brasil, v. 3, n. 4, p. 75-95, 2015. 


\section{ReLAInEP}

Acima de editores-chefes e coordenadores de reportagem está o Gerente de Redação e, acima dele, o Diretor de Jornalismo. Os telejornais são pautados por uma linha editorial preestabelecida e compartilhada entre todos os integrantes da equipe. Ao todo, a emissora possui 14 equipes de reportagem, formadas por repórteres, repórteres cinematográficos e auxiliares técnicos. Essas equipes se dividem entre os três telejornais diários e os programas especiais, que são exibidos nos fins de semana.

O Telejornal da hora do almoço possui de três a quatro equipes de reportagem produzindo material para o dia. Uma ou duas equipes também produz material para o telejornal no período da tarde. O deadline, prazo máximo para que as equipes retornem à redação para a edição da matéria, é 11 horas, mas sempre que há algum assunto factual há possibilidade de a equipe chegar mais tarde, dependendo do bloco em que a matéria vai ser exibida.

Também há possibilidade de geração de imagens e áudios por meio do equipamento que faz a transmissão ao vivo, o que facilita o trabalho e evita o deslocamento da equipe até a redação.

São realizadas duas reuniões diárias de pauta, uma pela manhã com as emissoras do interior e uma após o telejornal, que conta com a participação de toda a equipe. Nessa reunião, são apresentadas sugestões de pauta para o telejornal do dia seguinte.

Um dos problemas descritos pelos entrevistados foi a forma de apresentação das sugestões que ainda não foram checadas com as fontes. Eles consideram as propostas ainda não apuradas como ideias e não como sugestão de pauta, com dados e indicação de possíveis entrevistados. As ideias levadas para a reunião muitas vezes não se confirmam após a checagem e acabam gerando frustração, tanto para editores-chefes como para produtores.

Por outro lado, os entrevistados consideram que o maior estímulo para sugestão de pauta é o reconhecimento por um trabalho bem-feito e o desafio da busca de informações.

Uma das dificuldades do processo de produção de pauta de telejornal foi a necessidade de deslocamento para produção de imagens e entrevistas audiovisuais, o que exige uma logística bem programada pelo produtor e apresenta uma dependência muito grande das fontes.

Com a junção das entrevistas da observação, a partir do protocolo, foram identificadas 34 etapas da construção da pauta, elencadas na Tabela 2 (em anexo).

ReLAInEP - Revista Latino-America de Inovação e Engenharia de Produção, Curitiba, PR, Brasil, v. 3, n. 4, p. 75-95, 2015. 


\section{ReLAInEP}

\section{CONSIDERAÇÕES FINAIS}

Diferentemente de uma empresa comum, que busca vender um produto e com isso obter lucro, as empresas de comunicação voltadas para a produção de conteúdo jornalístico dependem da atração da audiência para obter anunciantes. O processo de criação de conteúdo jornalístico também é diferente e a criação de cada pauta pode ser comparada ao processo de criação de conhecimento descrito por Nonaka e Takeuchi.

Sendo assim, este estudo buscou identificar os elementos do processo de criação do conhecimento e avaliar as condições do ambiente de trabalho para a criação de pautas jornalísticas de um telejornal de uma emissora de televisão da Região Sul do Brasil.

A partir de entrevistas e do protocolo de observação, foram identificadas 34 etapas para a produção da pauta do telejornal estudado, com o envolvimento direto de pelo menos quinze jornalistas divididos em cinco funções diferentes: editores-chefes (2), editores (4), produtores (3), coordenadores de reportagem (3) e apresentadores/editores (3).

Apesar de qualquer pessoa poder sugerir uma pauta, incluindo as equipes externas e telespectadores, o produtor, profissional responsável pela pauta, tem como função principal buscar assuntos que possam ser relevantes para o telejornal. As sugestões são apresentadas, principalmente, na reunião de pauta que ocorre após a exibição do telejornal e contam com a participação de toda a equipe. Nessa reunião, são discutidos o formato, o enfoque, os possíveis entrevistados e os dados necessários para a produção. Porém, os entrevistados relataram que um dos principais problemas das sugestões de pauta é que, muitas vezes, os produtores chegam para a reunião com apenas uma ideia de pauta, sem a checagem completa que confirma se a matéria é viável ou não. Em contrapartida, o principal estímulo aos profissionais foi apontado como o reconhecimento por pautas desafiadoras.

Como o jornalismo é dinâmico e depende muito da cobertura de fatos sem qualquer aviso prévio ou possibilidade de planejamento, pode-se afirmar que a rotina da criação de conhecimento da pauta do telejornal é baseada no caos criativo, uma das condições capacitadoras para a criação do conhecimento. Além do caos criativo, as outras condições estão presentes na maioria das fases de criação da pauta: a intenção, que pode ser identificada como a linha editorial do telejornal; a autonomia, que permite a busca por fontes variadas para apuração de informações e marcação de entrevistas; a flutuação, já que os profissionais

ReLAInEP - Revista Latino-America de Inovação e Engenharia de Produção, Curitiba, PR, Brasil, v. 3, n. 4, p. 75-95, 2015. 


\section{ReLAInEP}

precisam sempre pensar em um formato inovador de mostrar aquela notícia comum, que precisa ser mostrada todos os anos em determinada época; a redundância, que é compartilhada diariamente durante a discussão de assuntos, quando se pergunta a quem se pretende atingir com determinada matéria, quantas pessoas serão beneficiadas ou informadas sobre o assunto e a variedade de requisitos, presente na forma de produção compartilhada pelo sistema online e a necessidade de que os produtores e demais jornalistas tenham conhecimento básico das mais variadas áreas que são mostradas nas reportagens.

O processo da espiral do conhecimento ocorre diariamente e começa com a ideia da pauta, "terminando" com a exibição da matéria e recomeça com a sugestão de continuidade de um telespectador ou de um integrante da equipe sobre uma forma de dar continuidade ao assunto.

Apesar da presença da maioria das condições capacitadoras da criação do conhecimento da pauta, há pouca utilização de metáforas e analogias sobre o perfil dos jornais, que atentem os produtores aos assuntos e temas que podem ser levantados e apresentados como sugestão.

Para estudos futuros, podem-se detalhar as ações e medidas já adotadas em empresas inovadoras que podem ser adotadas na rotina da produção do telejornalismo.

\section{REFERENCIAS}

ALVARENGA NETO, Rivadávia C. D. Gestão do Conhecimento em Organizações: Proposta de mapeamento conceitual integrativo. São Paulo: Saraiva, 2008.

GIL, A. C. Como elaborar projetos de pesquisa. São Paulo: Atlas, 2002.

HAUTALA, Johanna; JAUHIAINEN, Jussi S. Spatio-temporal process of knowledge creation. Research Policy, v. 43, n. 4, p. 655-668, 2014.

LIU, Xiang; MA, Feicheng. Transfer and distribution of knowledge creation activities of bioscientists in knowledge space. Scientometrics, v. 95, p. 299-310, 2013.

LLERENA, Patrick; OZMAN, Muge. Networks, irreversibility and knowledge creation. SpringerVerlag:J Evol Econ, v. 23, p. 431-453, 2013.

LEONARDI, Juliana ; BASTOS, Rogério Cid. Bases epistemológicas da teoria de criação do conhecimento organizacional. Perspectivas em Gestão \& Conhecimento, João Pessoa, v. 4, n. 2, p. 3-18, jul./dez., 2014.

ReLAInEP - Revista Latino-America de Inovação e Engenharia de Produção, Curitiba, PR, Brasil, v. 3, n. 4, p. 75-95, 2015. 


\section{ReLAInEP}

MCGEE, James; PRUSAK, Laurence. Gerenciamento Estratégico da Informação. Rio de Janeiro: Campus, 1994.

NONAKA, Ikujiro e TAKEUCHI, Hirotaka. Criação do Conhecimento na Empresa: como as empresas japonesas geram a dinâmica da inovação. Rio de Janeiro: Elsevier,1997.

NONAKA, Ikujiro e TAKEUCHI, Hirotaka. Gestão do conhecimento. Porto Alegre: Bookman, 2008.

PATERNOSTRO, Vera Íris. O texto na TV: Manual de Telejornalismo. Rio de Janeiro: Campus, 1999.

SETZER, Valdemar W. Dado, Informação, Conhecimento e Competência. DataGramaZero - Revista da Ciência da Informação - n. zero - dez., 1999.

SILVA, S. L. Gestão do conhecimento: uma revisão crítica orientada pela abordagem da criação do conhecimento. Ciência da Informação, Brasília, v. 33, n. 2, p. 143-151, maio/ago., 2004.

VON KROGH, Georg; ICHIJO, Kazuo; NONAKA, Ikujio. Facilitando a Criação de Conhecimento: Reinventando a Empresa com o Poder da Inovação Contínua. Rio de Janeiro: Campus, 2001.

Anexo- Tabela 2 Etapas para composição da pauta

\begin{tabular}{|l|l|l|l|l|}
$\begin{array}{l}\text { Etapas da construção } \\
\text { da pauta }\end{array}$ & Quem & $\begin{array}{l}\text { Modos de } \\
\text { conversão }\end{array}$ & $\begin{array}{l}\text { Tipo de } \\
\text { conhecimento }\end{array}$ & $\begin{array}{l}\text { Condições } \\
\text { Capacitadoras }\end{array}$ \\
\hline $\begin{array}{l}\text { Reunião de pauta da } \\
\text { manhã }\end{array}$ & $\begin{array}{l}\text { Editor-chefe, } \\
\text { editor e } \\
\text { editores das } \\
\text { emissoras } \\
\text { do interior } \\
\text { externalização }\end{array}$ & $\begin{array}{l}\text { Socialização e } \\
\text { Compartilhado e } \\
\text { conceitual }\end{array}$ & $\begin{array}{l}\text { Intenção, } \\
\text { autonomia, } \\
\text { Flutuação e caos } \\
\text { criativo, } \\
\text { redundância e } \\
\text { variedade de } \\
\text { requisitos }\end{array}$ \\
\hline $\begin{array}{l}\text { Levantamento dos } \\
\text { últimos } \\
\text { acontecimentos do dia } \\
\text { (factuais) e da agenda } \\
\text { do dia }\end{array}$ & $\begin{array}{l}\text { Produtores e } \\
\text { apuradores }\end{array}$ & Externalização & Sistêmico & $\begin{array}{l}\text { Intenção, } \\
\text { autonomia, } \\
\text { Flutuação e caos } \\
\text { criativo, } \\
\text { redundância e } \\
\text { variedade de } \\
\text { requisitos }\end{array}$ \\
\hline
\end{tabular}

ReLAInEP - Revista Latino-America de Inovação e Engenharia de Produção, Curitiba, PR, Brasil, v. 3, n. 4, p. 75-95, 2015. 


\begin{tabular}{|c|c|c|c|c|}
\hline $\begin{array}{l}\text { Etapas da construção } \\
\text { da pauta }\end{array}$ & Quem & $\begin{array}{l}\text { Modos de } \\
\text { conversão }\end{array}$ & $\begin{array}{l}\text { Tipo de } \\
\text { conhecimento }\end{array}$ & $\begin{array}{l}\text { Condições } \\
\text { Capacitadoras }\end{array}$ \\
\hline $\begin{array}{l}\text { Oferta de pautas a } \\
\text { partir dos factuais }\end{array}$ & $\begin{array}{l}\text { Produtora } \\
\text { da manhã }\end{array}$ & Combinação & Sistêmico & $\begin{array}{l}\text { Intenção, } \\
\text { redundância e } \\
\text { variedade de } \\
\text { requisitos }\end{array}$ \\
\hline $\begin{array}{l}\text { Reunião de definição } \\
\text { do espelho do jornal - } \\
\text { tempo aproximado de } \\
\text { cada matéria, ordem } \\
\text { de exibição, matérias } \\
\text { que serão chamadas na } \\
\text { escalada e nas } \\
\text { passagens de bloco }\end{array}$ & $\begin{array}{l}\text { Editor-chefe, } \\
\text { editores }\end{array}$ & $\begin{array}{l}\text { Socialização e } \\
\text { externalização }\end{array}$ & $\begin{array}{l}\text { Compartilhado e } \\
\text { conceitual }\end{array}$ & $\begin{array}{l}\text { Intenção, } \\
\text { autonomia, } \\
\text { Flutuação e caos } \\
\text { criativo e } \\
\text { redundância }\end{array}$ \\
\hline $\begin{array}{l}\text { Escolha de cobertura } \\
\text { de assuntos factuais }\end{array}$ & $\begin{array}{l}\text { Editores- } \\
\text { chefes }\end{array}$ & Combinação & Sistêmico & $\begin{array}{l}\text { Intenção, } \\
\text { redundância e } \\
\text { variedade de } \\
\text { requisitos }\end{array}$ \\
\hline $\begin{array}{l}\text { Escolha da equipe de } \\
\text { reportagem que vai } \\
\text { cobrir o factual e da } \\
\text { matéria que será } \\
\text { desmarcada }\end{array}$ & $\begin{array}{l}\text { Editores- } \\
\text { chefes e } \\
\text { coordenador } \\
\text { de } \\
\text { reportagem }\end{array}$ & Combinação & Sistêmico & $\begin{array}{l}\text { Intenção, } \\
\text { redundância e } \\
\text { variedade de } \\
\text { requisitos }\end{array}$ \\
\hline $\begin{array}{l}\text { Distribuição da pauta } \\
\text { para as equipes de } \\
\text { reportagem }\end{array}$ & $\begin{array}{l}\text { Coordenaçã } \\
\text { o de } \\
\text { reportagem }\end{array}$ & Combinação & Sistêmico & $\begin{array}{l}\text { Intenção, } \\
\text { redundância e } \\
\text { variedade de } \\
\text { requisitos }\end{array}$ \\
\hline $\begin{array}{l}\text { Leitura da pauta pelas } \\
\text { equipes de reportagem }\end{array}$ & $\begin{array}{l}\text { Repórter e } \\
\text { repórter } \\
\text { cinematográ } \\
\text { fico }\end{array}$ & Internalização & Operacional & $\begin{array}{l}\text { Intenção e } \\
\text { redundância }\end{array}$ \\
\hline $\begin{array}{l}\text { Conversa com editores- } \\
\text { chefes ou editores } \\
\text { antes de sair para a } \\
\text { produção da matéria }\end{array}$ & $\begin{array}{l}\text { Repórteres e } \\
\text { repórteres } \\
\text { cinematográ } \\
\text { ficos }\end{array}$ & Socialização & Compartilhado & $\begin{array}{l}\text { Intenção, } \\
\text { autonomia, } \\
\text { Flutuação e caos } \\
\text { criativo, } \\
\text { redundância e } \\
\text { variedade de } \\
\text { requisitos }\end{array}$ \\
\hline $\begin{array}{l}\text { Gravação de } \\
\text { entrevistas e imagens } \\
\text { para a produção da } \\
\text { reportagem }\end{array}$ & $\begin{array}{l}\text { Equipe de } \\
\text { reportagem }\end{array}$ & Externalização & Conceitual & $\begin{array}{l}\text { Intenção, } \\
\text { autonomia, } \\
\text { Flutuação e caos } \\
\text { criativo, } \\
\text { redundância e } \\
\text { variedade de } \\
\text { requisitos }\end{array}$ \\
\hline
\end{tabular}

ReLAInEP - Revista Latino-America de Inovação e Engenharia de Produção, Curitiba, PR, Brasil, v. 3, n. 4, p. 75-95, 2015. 


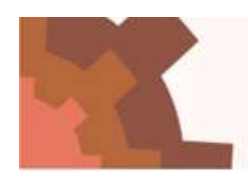

\section{ReLAInEF}

\begin{tabular}{|c|c|c|c|c|}
\hline $\begin{array}{l}\text { Etapas da construção } \\
\text { da pauta }\end{array}$ & Quem & $\begin{array}{l}\text { Modos de } \\
\text { conversão }\end{array}$ & $\begin{array}{l}\text { Tipo de } \\
\text { conhecimento }\end{array}$ & $\begin{array}{l}\text { Condições } \\
\text { Capacitadoras }\end{array}$ \\
\hline $\begin{array}{l}\text { Planejamento diário } \\
\text { para distribuição de } \\
\text { equipes entre os } \\
\text { telejornais da emissora } \\
\text { e definição de } \\
\text { produções para o } \\
\text { telejornal das } 12 \mathrm{~h} \text { que } \\
\text { serão feitas durante o } \\
\text { período da tarde. }\end{array}$ & $\begin{array}{l}\text { Produtora } \\
\text { da manhã e } \\
\text { coordenação } \\
\text { de } \\
\text { reportagem }\end{array}$ & Combinação & Sistêmico & $\begin{array}{l}\text { Intenção, } \\
\text { redundância e } \\
\text { variedade de } \\
\text { requisitos }\end{array}$ \\
\hline $\begin{array}{l}\text { Definição de entrada } \\
\text { ao vivo no telejornal } \\
\text { com assuntos do dia e } \\
\text { escolha da equipe de } \\
\text { reportagem }\end{array}$ & $\begin{array}{l}\text { Editores- } \\
\text { chefes e } \\
\text { coordenação } \\
\text { de } \\
\text { reportagem }\end{array}$ & Combinação & Sistêmico & $\begin{array}{l}\text { Intenção, } \\
\text { redundância e } \\
\text { variedade de } \\
\text { requisitos }\end{array}$ \\
\hline $\begin{array}{l}\text { Marcação com fonte } \\
\text { para a entrevista ao } \\
\text { vivo ou apuração de } \\
\text { informações sobre o } \\
\text { tema }\end{array}$ & Produtores & Combinação & Sistêmico & $\begin{array}{l}\text { Intenção, } \\
\text { redundância e } \\
\text { variedade de } \\
\text { requisitos }\end{array}$ \\
\hline $\begin{array}{l}\text { Apuração de } \\
\text { informações para } \\
\text { matérias que estão em } \\
\text { processo de produção } \\
\text { para o dia, como notas } \\
\text { oficiais de } \\
\text { posicionamento ou } \\
\text { dados que possam } \\
\text { melhorar a } \\
\text { contextualização da } \\
\text { matéria }\end{array}$ & Produtores & $\begin{array}{l}\text { Combinação e } \\
\text { internalização }\end{array}$ & $\begin{array}{l}\text { Sistêmico e } \\
\text { operacional }\end{array}$ & $\begin{array}{l}\text { Intenção, } \\
\text { redundância e } \\
\text { variedade de } \\
\text { requisitos }\end{array}$ \\
\hline $\begin{array}{l}\text { Construção do texto no } \\
\text { Avid }\end{array}$ & Repórteres & Combinação & Sistêmico & $\begin{array}{l}\text { Intenção, } \\
\text { redundância e } \\
\text { variedade de } \\
\text { requisitos }\end{array}$ \\
\hline $\begin{array}{l}\text { Edição do material } \\
\text { audiovisual }\end{array}$ & Editores & Combinação & Sistêmico & $\begin{array}{l}\text { Intenção, } \\
\text { redundância e } \\
\text { variedade de } \\
\text { requisitos }\end{array}$ \\
\hline $\begin{array}{l}\text { Finalização do espelho } \\
\text { do telejornal }\end{array}$ & $\begin{array}{l}\text { Editores- } \\
\text { chefes }\end{array}$ & Combinação & Sistêmico & $\begin{array}{l}\text { Intenção, } \\
\text { redundância e } \\
\text { variedade de } \\
\text { requisitos }\end{array}$ \\
\hline Exibição do telejornal & $\begin{array}{l}\text { Telespectad } \\
\text { ores }\end{array}$ & Internalização & Operacional & Intenção \\
\hline
\end{tabular}

ReLAInEP - Revista Latino-America de Inovação e Engenharia de Produção, Curitiba, PR, Brasil, v. 3, n. 4, p. 75-95, 2015. 


\begin{tabular}{|c|c|c|c|c|}
\hline $\begin{array}{l}\text { Etapas da construção } \\
\text { da pauta }\end{array}$ & Quem & $\begin{array}{l}\text { Modos de } \\
\text { conversão }\end{array}$ & $\begin{array}{l}\text { Tipo de } \\
\text { conhecimento }\end{array}$ & $\begin{array}{l}\text { Condições } \\
\text { Capacitadoras }\end{array}$ \\
\hline $\begin{array}{l}\text { Reunião de pauta } \\
\text { diária, após o telejornal }\end{array}$ & $\begin{array}{l}\text { Produtores, } \\
\text { editores, } \\
\text { coordenação } \\
\text { de } \\
\text { reportagem } \\
\text { e editores- } \\
\text { chefes }\end{array}$ & $\begin{array}{l}\text { Combinação e } \\
\text { socialização }\end{array}$ & $\begin{array}{l}\text { Sistêmico e } \\
\text { compartilhado }\end{array}$ & $\begin{array}{l}\text { Intenção, } \\
\text { autonomia, } \\
\text { Flutuação e caos } \\
\text { criativo, } \\
\text { redundância e } \\
\text { variedade de } \\
\text { requisitos }\end{array}$ \\
\hline $\begin{array}{l}\text { Avaliação do telejornal } \\
\text { do dia }\end{array}$ & $\begin{array}{l}\text { Toda a } \\
\text { equipe }\end{array}$ & Externalização & Conceitual & $\begin{array}{l}\text { Intenção, } \\
\text { autonomia, } \\
\text { Flutuação e caos } \\
\text { criativo, } \\
\text { redundância e } \\
\text { variedade de } \\
\text { requisitos }\end{array}$ \\
\hline $\begin{array}{l}\text { Sugestão de ideias } \\
\text { ainda não apuradas }\end{array}$ & $\begin{array}{l}\text { Toda a } \\
\text { equipe }\end{array}$ & Socialização & Compartilhado & $\begin{array}{l}\text { Intenção, } \\
\text { autonomia, } \\
\text { Flutuação e caos } \\
\text { criativo }\end{array}$ \\
\hline $\begin{array}{l}\text { Sugestões de temas já } \\
\text { apurados }\end{array}$ & $\begin{array}{l}\text { Produtores, } \\
\text { repórteres }\end{array}$ & Externalização & Conceitual & $\begin{array}{l}\text { Intenção, } \\
\text { autonomia, } \\
\text { Flutuação e caos } \\
\text { criativo, } \\
\text { redundância e } \\
\text { variedade de } \\
\text { requisitos }\end{array}$ \\
\hline $\begin{array}{l}\text { Sugestões dos } \\
\text { telespectadores não } \\
\text { apuradas }\end{array}$ & Produtores & Socialização & Compartilhado & $\begin{array}{l}\text { Intenção, } \\
\text { autonomia, } \\
\text { Flutuação e caos } \\
\text { criativo }\end{array}$ \\
\hline $\begin{array}{l}\text { Sugestões dos } \\
\text { telespectadores já } \\
\text { apuradas }\end{array}$ & Produtores & Externalização & Conceitual & $\begin{array}{l}\text { Intenção, } \\
\text { autonomia, } \\
\text { Flutuação e caos } \\
\text { criativo, } \\
\text { redundância e } \\
\text { variedade de } \\
\text { requisitos }\end{array}$ \\
\hline $\begin{array}{l}\text { Aprovação dos temas } \\
\text { que precisam ser mais } \\
\text { apurados para } \\
\text { marcação de matérias }\end{array}$ & $\begin{array}{l}\text { Editores- } \\
\text { chefes e } \\
\text { produtores }\end{array}$ & $\begin{array}{l}\text { Combinação e } \\
\text { internalização }\end{array}$ & $\begin{array}{l}\text { Sistêmico e } \\
\text { operacional }\end{array}$ & $\begin{array}{l}\text { Intenção, } \\
\text { redundância e } \\
\text { variedade de } \\
\text { requisitos }\end{array}$ \\
\hline $\begin{array}{l}\text { Seleção de quais } \\
\text { pautas serão } \\
\text { produzidas no dia } \\
\text { seguinte }\end{array}$ & $\begin{array}{l}\text { Editores- } \\
\text { chefes e } \\
\text { coordenador } \\
\text { es }\end{array}$ & Combinação & Sistêmico & $\begin{array}{l}\text { Intenção, } \\
\text { redundância e } \\
\text { variedade de } \\
\text { requisitos }\end{array}$ \\
\hline
\end{tabular}

ReLAInEP - Revista Latino-America de Inovação e Engenharia de Produção, Curitiba, PR, Brasil, v. 3, n. 4, p. 75-95, 2015. 


\begin{tabular}{|c|c|c|c|c|}
\hline $\begin{array}{l}\text { Etapas da construção } \\
\text { da pauta }\end{array}$ & Quem & $\begin{array}{l}\text { Modos de } \\
\text { conversão }\end{array}$ & $\begin{array}{l}\text { Tipo de } \\
\text { conhecimento }\end{array}$ & $\begin{array}{l}\text { Condições } \\
\text { Capacitadoras }\end{array}$ \\
\hline $\begin{array}{l}\text { Reunião semanal de } \\
\text { pauta }\end{array}$ & $\begin{array}{l}\text { Toda a } \\
\text { equipe }\end{array}$ & $\begin{array}{l}\text { Socialização e } \\
\text { externalização }\end{array}$ & $\begin{array}{l}\text { Compartilhado e } \\
\text { conceitual }\end{array}$ & $\begin{array}{l}\text { Intenção, } \\
\text { autonomia, } \\
\text { Flutuação e caos } \\
\text { criativo, } \\
\text { redundância e } \\
\text { variedade de } \\
\text { requisitos }\end{array}$ \\
\hline $\begin{array}{l}\text { Registro das sugestões } \\
\text { de pauta aprovadas na } \\
\text { pasta "Sugestões" no } \\
\text { Avid }\end{array}$ & $\begin{array}{l}\text { Coordenado } \\
\text { r de } \\
\text { reportagem }\end{array}$ & Combinação & Sistêmico & $\begin{array}{l}\text { Intenção, } \\
\text { redundância e } \\
\text { variedade de } \\
\text { requisitos }\end{array}$ \\
\hline $\begin{array}{l}\text { Reunião de produtores } \\
\text { com a coordenação de } \\
\text { reportagem para } \\
\text { definir as pautas, } \\
\text { horário de produção e } \\
\text { distribuição dos } \\
\text { assuntos entre equipes } \\
\text { de reportagem no } \\
\text { próximo dia }\end{array}$ & $\begin{array}{l}\text { Produtores e } \\
\text { coordenação } \\
\text { de } \\
\text { reportagem }\end{array}$ & Combinação & Sistêmico & $\begin{array}{l}\text { Intenção, } \\
\text { redundância e } \\
\text { variedade de } \\
\text { requisitos }\end{array}$ \\
\hline $\begin{array}{l}\text { Apuração de } \\
\text { informações sobre } \\
\text { tema definido na } \\
\text { reunião do telejornal }\end{array}$ & Produtores & $\begin{array}{l}\text { Externalização e } \\
\text { combinação }\end{array}$ & $\begin{array}{l}\text { Sistêmico e } \\
\text { conceitual }\end{array}$ & $\begin{array}{l}\text { Intenção, } \\
\text { autonomia, } \\
\text { Flutuação e caos } \\
\text { criativo, } \\
\text { redundância e } \\
\text { variedade de } \\
\text { requisitos }\end{array}$ \\
\hline $\begin{array}{l}\text { Afinamento do } \\
\text { enfoque e gancho da } \\
\text { matéria }\end{array}$ & $\begin{array}{l}\text { Produtores, } \\
\text { editores- } \\
\text { chefes e } \\
\text { coordenação } \\
\text { de } \\
\text { reportagem }\end{array}$ & Combinação & Sistêmico & $\begin{array}{l}\text { Intenção, } \\
\text { redundância e } \\
\text { variedade de } \\
\text { requisitos }\end{array}$ \\
\hline $\begin{array}{l}\text { Marcação de } \\
\text { entrevistas com } \\
\text { definição de horário, } \\
\text { local e entrevistado }\end{array}$ & Produtores & Combinação & Sistêmico & $\begin{array}{l}\text { Intenção, } \\
\text { redundância e } \\
\text { variedade de } \\
\text { requisitos }\end{array}$ \\
\hline $\begin{array}{l}\text { Definição de um } \\
\text { repórter para produção }\end{array}$ & $\begin{array}{l}\text { Editores- } \\
\text { chefes e } \\
\text { coordenador } \\
\text { es }\end{array}$ & Combinação & Sistêmico & $\begin{array}{l}\text { Intenção, } \\
\text { redundância e } \\
\text { variedade de } \\
\text { requisitos }\end{array}$ \\
\hline $\begin{array}{l}\text { Produção da pauta no } \\
\text { Avid }\end{array}$ & Produtores & $\begin{array}{l}\text { Externalização e } \\
\text { combinação }\end{array}$ & $\begin{array}{l}\text { Sistêmico e } \\
\text { conceitual }\end{array}$ & $\begin{array}{l}\text { Intenção, } \\
\text { autonomia, } \\
\text { Flutuação e caos } \\
\text { criativo, } \\
\text { redundância e } \\
\text { variedade de } \\
\text { requisitos }\end{array}$ \\
\hline
\end{tabular}

Fonte: os autores (2014)

ReLAInEP - Revista Latino-America de Inovação e Engenharia de Produção, Curitiba, PR, Brasil, v. 3, n. 4, p. 75-95, 2015. 
ReLAInEP - Revista Latino-America de Inovação e Engenharia de Produção, Curitiba, PR, Brasil, v. 3, n. 4, p. 75-95, 2015. 